\title{
Ignacio Ellacuría: la dimensión práxica de las posibilidades
}

Rubén Fúnez ${ }^{1}$

Recibido en Enero 2013, aprobado en Mayo 2013

Resumen.

En este artículo queremos exponer la noción de posibilidades en la filosofía de Ellacuría y describir como la situación histórica a la que tuvo que responder, fue la que lo capacitó para aprehender tanto su dimensión ética, como su dimensión practica.

Palabras clave:

Posibilidades, apropiación de posibilidades, capacitación, posibilidades posibilitantes

\section{Abstract}

The aim of this article is to present the notion of possibilities in Ellacuria's philosophical work and to describe how his historical reality allowed him to apprehend both an ethical and a practical dimension.

\section{Keywords}

Possibilities, apprehension of possibilities, capacitation, possibilitating possibilities

\section{Introducción}

Zubiri estaba convencido que la filosofía requiere de una experiencia fundante ${ }^{2}$. Es justamente esa experiencia la que le da su toque personal e histórico al esfuerzo filosófico. La filosofía de Ellacuría no está exenta de esta experiencia fundante, estuvo determinada por la situación en la que le tocó desarrollarse: la situación salvadoreña de las décadas de los setenta y ochenta.

1 Licenciado en Filosofía, Maestría en Teología y Doctor en Filosofía. Profesor de la Universidad Don Bosco. E-mail: ruben.funez@udb.edu.sv.

2 X. Zubiri, Naturaleza, Historia Dios, p. 189. 
Para enmarcar este artículo interesa destacar cuatro cosas. La primera acentúa el esfuerzo de Ellacuría por leer la filosofía zubiriana desde la noción de praxis histórica ${ }^{3}$, en este sentido la reflexión de Ellacuría concreta muchos de los planteamientos epistemológicos de Zubiri, respecto al tema de las posibilidades. La segunda es que se va a exponer a Ellacuría desde Ellacuría mismo, esto quiere decir que aunque sepamos que se trata de temas abordados, tratados y estudiados por Zubiri, al ser tratados por Ellacuría este los hace suyos y los incorpora en su propia filosofía 4 . La tercera es que precisamente por lo anterior, todos los ejemplos a los que aquí se van a recurrir para hacer comprensible el pensamiento de Ellacuría están tomados de la realidad con la que se sintió obligado no sólo de hacerse cargo, ni de encargarse sino de cargar con ella, con lo que está en juego, como lo recuerda H. Samour, la propia realización humana ${ }^{5}$. Finalmente, la cuarta, toda la exposición va a girar en torno a Filosofía de la realidad histórica. Obra que vamos a citar con la sigla, FRH.

En general, queremos demostrar que el gran aporte al tratamiento de las posibilidades llevado a cabo por Ignacio Ellacuría, fue insistir en su dimensión práxica. Es importante decirlo dado que la tarea que este pensador tiene pendiente de esclarecer, es precisamente la dimensión de posibilidad de los hechos históricos.

3 Que no se trata de una interpretación antojadiza, sino que se trata de un esfuerzo genuino por comprender la novedad del pensamiento de I. Ellacuría, lo confirma J. A. Senent cuando dice que este esfuerzo de interpretación se inscribe precisamente en el nuevo horizonte de intelección que busca aquel pensador para la filosofía. "Este nuevo horizonte será entendido y formulado desde la idea de praxis histórica. Por praxis histórica está entendiendo la totalidad del proceso social en cuanto transformador de la realidad tanto natural como histórica", J.A. Senent de Frutos, Ellacuría y los derechos humanos, p. 130. Héctor Samour por su parte, en la exposición que hace del carácter práxico y abierto de la realidad humana dice que "Ellacuría destaca que esta actualización es un ejercicio físico del carácter absoluto del animal de realidades; y esto significa que se trata de una afirmación práxica de su propia realidad en el mundo de lo real mediante el cual se va constituyendo su ser, su Yo" H. Samour, Voluntad de liberación, la filosofía de Ignacio Ellacuría, p. 52. Y más adelante afirma que "el gran empeño de Ellacuría fue explotar la veta práxica de la filosofía zubiriana y proponer desde ella un modelo de filosofía realista y práctica superior a los ahora vigentes, cuya expresión máxima fue precisamente su Filosofía de la realidad histórica", Op. Cit. p. 167. Finalmente, J. C. Scannone recuerda que se trata de un esfuerzo típico del quehacer filosófico latinoamericano. Scannone dice que "la FL es también -aunque no solamente- un nuevo modo de practicar la filosofía de la historia. Pues ella reflexiona críticamente la acción y la pasión históricas para contribuir con sus planteos teóricos, a transformarlas en más humanas. Pero dicha filosofía no solamente intenta criticar los supuestos ideológicos -aun seudofilosóficos- de la dominación, ni sólo llevar a concepto la situación para discernirla, interpretarla, comprenderla e iluminar los caminos de su superación. Pues desde la nueva praxis así alcanzada, se replantea luego, a partir del nuevo horizonte abierto por ésta, todas las grandes cuestiones del hombre y, por eso mismo, de la filosofía, para responder a ellas con un pensamiento nuevo" J. C Scannone, "La filosofía de la liberación: historia, características, vigencia actual”, disponible en http://es.scribd. $\mathrm{com} / \mathrm{doc} / 87004093 /$ La-Filosofia-de-La-Liberacion-Historia-Caracteristicas-Vigencia-Actual-JuanCarlos-Scannone.

4 El mismo Ellacuría justifica este modo de proceder al afirmar que "podrá intentarse hacer lo mismo, pero entonces lo mismo aparecerá en una forma distinta de la anterior, en forma de repetición, repetición de aquello que no era repetición". I. Ellacuría, Filosofía de la realidad histórica, p. 498.

5 H. Samour, Op. Cit, p. 92. 


\section{Definición de historia}

\subsection{Hechos históricos}

A El Salvador le han ocurrido muchos hitos de relevante importancia en su historia: la matanza de 1932, la guerra civil, los Acuerdos de paz, por mencionar algunos. Respecto a estos sucesos es legítimo preguntarse, ¿se trata de meros hechos? ¿Son hechos históricos? ¿Son hechos porque son históricos o son históricos porque son hechos? ${ }^{6}$ ¿Qué es lo que hace que los tratemos como históricos? ¿Tiene alguna importancia para la filosofía plantearnos estas inquietudes?

Es un hecho que en 1932 hubo un levantamiento en el que murieron varios miles de Indígenas ${ }^{7}$. La inquietud a la que hay que responder es por qué se trata de un hecho, o mejor ¿qué es un hecho? Establezcamos que llamamos hecho a aquello que por su propia índole puede ser observado por cualquiera. En este sentido, un hecho tiene el mismo carácter que la gravitación universal, que la inercia, etc. Planteado lo anterior hay que decir también que ocurren hechos que no son susceptibles de ser vistos por cualquiera, por ejemplo la aparición de la virgen, una determinada y concreta interpretación de una película, etc. Esto fuerza a distinguir entre positum y hecho. Algo puede ser positum y no necesariamente ser un hecho. Como recuerda X. Zubiri, "en cuanto es un positum, el hecho es algo que está presente, que sólo está presente, y que lo está en su presentar mismo [...]. Pero no todo lo intelectivamente observable es forzosamente un hecho. Para serlo ha de cumplir con una inexorable condición: es necesario que el positum, además de observable, sea por su propia índole observable para cualquiera" (IRA 182).

Hemos definido lo qué es un hecho. Sin embargo, lo que aquí importa aclarar es ¿qué es un hecho histórico? Dejar caer una piedra en caída libre es un hecho, pero ¿se trata de un hecho histórico? Que la piedra caiga es un hecho natural, es decir se dan ciertas condiciones a partir de las cuales es posible establecer que todo objeto dejado en suspenso tiende a caer hacia el centro de la tierra. No obstante, el que sea un hecho físico ${ }^{8}$ no significa que sea automáticamente algo histórico.

¿Qué hace que un hecho sea histórico? Consideremos la caída de un cuerpo humano desde el quinto piso de un edificio. La ciencia explicaría la caída, del

6 Nos estamos refiriendo a los sucesos apuntados. Si se tratara de la caída de los objetos, quizá no nos preguntaríamos si son hechos porque son históricos o si son históricos porque son hechos.

7 Dice E. Ching que "certeramente se puede decir que varios miles de personas fueron asesinadas",

E. Ching, “El levantamiento de 1932”, p. 66.

8 Escribimos físico en cursivas, para distinguir el sentido que tiene físico en la ciencia del sentido que tiene en la historia de la filosofía. 
mismo modo que explica la caída de una manzana`. Sin embargo, esa explicación resulta desde todo punto de vista insuficiente; a nosotros no nos interesa, para dar cuenta de aquella caída, la gravitación universal, sino las razones últimas de haberse lanzado al vacío; nos interesa caer en la cuenta de todas las posibilidades que entraron en juego. ¿Por qué eligió tirarse desde un quinto piso y no optó por cualquier otra posibilidad? De este modo lo que se busca es una serie de razones que expliquen por qué dicho individuo decidió suicidarse lanzándose desde un quinto piso. Si suprimimos toda posible elucubración y nos centramos en lo que ocurre, lo único dable de decir es que dicho individuo contaba con una serie de alternativas y, sin embargo, optó por una de ellas. Ese momento de la opción es algo con lo que no cuentan las leyes naturales. Un objeto suspendido a veinte metros del suelo, no cuenta con la posibilidad de caer hacia arriba ${ }^{10}$, inexorablemente va a caer hacia el centro de la tierra. No contar con la posibilidad de optar, es la razón central de que se trate de un mero hecho, Pero el hecho de que pueda optar hace de ello algo histórico.

Las posibilidades tienen un aspecto cognoscitivo, en la medida en la que son posibilidades para el conocimiento; tienen un aspecto pragmático en la medida en la que son posibilidades para la acción. Ninguna acción sería posible si no se contaran con posibilidades; tienen un aspecto ético, en la medida en la que con esas posibilidades la acción se orienta hacia determinada dirección, se puede aliviar los males por los que atraviesa nuestro mundo o se puede fomentar más el dolor. Como se trata de unos hechos que tienen una apoyatura natural, es necesario comenzar a identificar la relación que hay entre naturaleza e historia.

\subsection{Naturaleza e historia}

¿Dónde estriba la importancia de distinguir entre naturaleza e historia? En primer lugar es posible que se incurra en el error de confundir naturaleza e historia. En el caso que identifiquemos la historia con la evolución es evidente que estamos entendiendo o la evolución como algo histórico o lo histórico como algo evolutivo. No nos interesa en este caso indicar la índole ni de la evolución, ni la índole de la historia entendida como evolución, sino dejar constatado que la confusión es posible. Donde mejor corroboramos dicha confusión, es cuando hablamos de una historia natural, porque emparejamos dos esferas de competencia diversas (cf. FRH 165).

¿Qué importancia tiene evitar la identificación entre naturaleza e historia? La importancia estriba en que si identificamos historia con evolución se pierde lo

9 Cf. X, Zubiri, Sobre el Hombre p. 359.

10 Nos referimos al hecho de que dicho objeto quede suspendido en la tierra. 
estrictamente histórico, y lo que se quiere es tener una comprensión adecuada de la historia. A los individuos les pasan cosas, a la sociedad y a los países les pasan cosas, ¿dónde está lo histórico en eso que les pasa? Hay que preguntarse si los acontecimientos son históricos porque son acontecimientos, o más bien si son acontecimientos porque son históricos. Más específicamente hay que preguntarse ¿por qué los Acuerdos de paz, por ejemplo, son históricos? ${ }^{11}$ Esta es la cuestión.

Si se identifica evolución con historia o, en general, naturaleza con historia, difícilmente vamos a poder responder a la inquietud planteada. Pero la identificación es sólo un aspecto de la cuestión. Puede ocurrir que en lugar de la identificación, lo que ocurra sea la absorción de la historia por la naturaleza. Esta absorción puede ser entendida del modo siguiente: la naturaleza tiene sus estrictos y rigurosos dinamismos y es justo a ese dinamismo que se llama historia. Sin embargo, la historia no es algo distinto a lo que la naturaleza es de suyo; la naturaleza es desde sí misma y por sí misma dinámica y un modo de tener intelección de ese dinamismo es llamándole historia.

La absorción de la historia por la naturaleza, es el peligro de todos los materialismos, la explicación última de todos los fenómenos es la materia, una materia en movimiento, una materia dinámica. El peligro es que no hay cabida para la historia, para lo histórico. Rigurosamente hablando lo ocurrido, por ejemplo, con los Acuerdos de Paz, es producto mismo de la evolución de todo lo real; los cambios no son producidos por la revolución sino que se trata de los cambios necesarios que va exigiendo la evolución. Aquel hecho se explica del mismo modo que puede explicarse que los peces desarrollen patas y pulmones (cf. FRH 167).

Pero puede darse el caso contrario, y que sea la naturaleza la que quede absorbida en la historia. La historia no tiene nada que ver con la naturaleza. Si en el primer caso teníamos una naturaleza sin historia, en este caso tenemos una historia sin naturaleza, es el peligro de todos los idealismos. De lo que se trata es no de identificar la naturaleza con la historia, ni que la una quede absorbida en la otra, sino de establecer la apoyatura natural que tiene la historia. La historia no se sostiene en sí misma, sino que se sostiene en la naturaleza, aunque no se confundan, por eso Ellacuría se ve precisado a recordar que "la historia no flota sobre sí misma" (FRH 492).

11 Un brillante historiador salvadoreño, piensa que la proliferación de libros sobre lo ocurrido en la guerra civil salvadoreña, (los comandantes están contando sus peripecias en la guerra), en lugar de aclarar lo estrictamente histórico de dichos acontecimientos, puede más bien dificultar el estudio histórico de dichos sucesos (Conversación con Carlos Gregorio López). 
Lo que aquí se nos impone es reflexionar acerca de dicha apoyatura, ¿cómo se apoya la historia en la naturaleza?, o, como lo plantea I. Ellacuría, “¿en qué coinciden y en qué se diferencian la continuidad específica y la sucesión histórica?". Punto que es esencial clarificarlo en tanto que las coincidencias pueden inducir al error de identificarlas y las diferencias pueden inducir al error de pensar que no tienen nada que ver entre sí, con lo cual la noción de historia perdería una dimensión esencial para su comprensión (FRH 493) $)^{12}$.

En la articulación entre naturaleza e historia pueden identificarse tres importantes momentos. El primero de ellos es la transmisión de elementos psico-orgánicos. El segundo, la realidad humana es una radical unidad psicoorgánica. Toda realidad es algo abierto, en el caso de los hombres se trata de una apertura a distintas formas de estar en la realidad. Hay que distinguir entre la apertura, es decir entre algo estrictamente biológico, y las formas de estar en la realidad, algo que va abriendo la dimensión de historia. El tercero es el poder optar por una de esas formas de estar en la realidad.

En definitiva, los elementos psico-orgánicos, la apertura a formas de estar en la realidad y la opción por una de esas formas es lo que en rigor nos permite hablar de una articulación entre naturaleza e historia. Por ello Ellacuría dice que "la historia tiene así, como cualquier otra estructura humana, una precisa articulación: es unitariamente transmisión y tradición, aunque la razón formal de lo histórico esté en la tradición y no en la transmisión” (FRH 497).

\subsection{Entrega biológica}

Con respecto a la entrega biológica no hay mayor problema, lo que se entrega son notas psíquicas y orgánicas. No se trata de algo que les toque a los individuos decidir si se aceptan o no; a ningún ser humano se le preguntó previamente que psiquismo quería o que organismo quería; la estructura psicorgánica se trae y no hay nada que hacer. En un primer momento también ocurre lo mismo con lo histórico, al recién nacido se le entrega un modo humano de estar en la realidad. Modo en el que se puede distinguir también una dimensión cuasi biológica y la dimensión estrictamente histórica. La dimensión cuasi biológica es que aprehenda las cosas como reales, radicalmente ese es el modo humano de estar en la realidad, enfrentándose con las cosas como reales, pero también esta formalidad viene en la misma entrega biológica, y la dimensión rigurosamente histórica estriba no tanto en la aprehensión de las cosas como reales, sino en las posibilidades que se le entregan al recién nacido. Es evidente

12 Ellacuría dice que "creer que la historia no tiene que ver con la evolución biológica es una forma de idealismo y de falsificación de la historia; pero, al mismo tiempo, creer que la historia es sustancialmente lo mismo que la evolución es también una falsificación de la historia, un materialismo injustificado de la historia, una naturalización injustificada de lo histórico" (FRH 102). 
que tiene mejores posibilidades el que nace en la abundancia que el niño que es abandonado al nacer. Por el momento hay que fijarse no tanto en la dimensión material de las posibilidades, es decir, que sean tales o cuales posibilidades, sino en su dimensión formal, por lo tanto, que se trata de posibilidades que son entregadas, hay que fijarse en el momento de entrega y preguntarse cuáles son los momentos estructurales de esa entrega, de esa tradición ${ }^{13}$ (cf. FRH 498).

\subsection{Momentos estructurales de la tradición}

La tradición tiene tres momentos: el constituyente, el continuante y el progrediente. La entrega constituye el modo de estar en la realidad, en el mismo sentido en el que se dice tal rasgo lo constituye. En terminología zubiriana, el momento constituyente es el momento esencial de la entrega, toda forma de realidad supone haber sido entregada. En definitiva, la entrega tiene un momento constituyente del modo de estar en la realidad. Pero este momento es histórico, por lo tanto encierra en sí mismo ese dinamismo histórico. Es importante evitar el riesgo de reducir la entrega al hecho de provenir un ser humano de otro ser humano. Aquí lo que importa es el modo cómo está el ser humano a quien se le hace la entrega, y ese estar no se agota en sí mismo sino que encierra cierta pretensión, encierra la posibilidad de un devenir histórico susceptible de ser proseguido, en este sentido la entrega tiene como segundo momento estructural el que sea continuante. Ellacuría dice que precisamente por este momento es imposible la repetición en la historia. La entrega es constituyente y continuante en vista a la vida que cada ser humano ${ }^{14}$ va a realizar, en este sentido, la entrega es progrediente (cf. FRH 497-499).

El momento de la entrega es el momento en el que mejor se acentúa no sólo el dinamismo de la historia, algo que de algún modo lo habíamos conseguido con el momento continuante, sino que se acentúa la dimensión práxica de la historia. La historia es rigurosamente un dinamismo práxico. Ellacuría está interesado en exponer esa dimensión práxica de los momentos estructurales de la tradición y entiende por praxis a aquello que permite que los hombres vayan realizando su vida, es decir, asumiendo su vida realmente, haciéndose cargo de ella y optando por una u otra forma de realidad. Estamos instalados justo en la raíz de la historia, y toda la reflexión anterior versa sobre dicha raíz ${ }^{15}$, es decir estamos instalados en la pregunta por la tradición, por la entrega.

13 Entrega se dice en latín tradicio, por eso hablamos de tradición.

14 En el caso que lo que importe sea el carácter social de la entrega, entonces tendríamos que decir que los momentos constituyentes y continuantes son en vista de la forma de vida que va a realizar el grupo, la raza, la sociedad, el pueblo, etc. Es decir, los momentos estructurales no se limitan a ser momentos del individuo, son momentos estructurales de la especie, aquí, por comodidad nos hemos limitado a exponerlo desde el punto de vista del individuo.

15 Es importante esta observación porque I. Ellacuría aclara que no es formalmente el mismo problema el que se refiere al sujeto de la historia y el que lo hace con relación al sujeto de la tradición. Lo que aquí expone es precisamente el sujeto de la tradición (cf. FRH 500). 


\subsection{Sujeto de la tradición}

El problema que aquí se plantea es acerca de quién entrega. Si hay una entrega necesariamente habrá alguien que entregue. ¿Qué importancia tiene el tratamiento de este tema? A Ellacuría no le es indiferente la discusión que hay desde santo Tomás de Aquino acerca de la relación entre el todo y la parte ${ }^{16}$. Por eso lo que aquí le interesa es señalar cómo el todo afecta a la parte. En otras palabras, como lo social afecta al individuo. En este sentido aparecen dos tipos de sujetos, el vector de la tradición y los individuos, es decir la especie y su refluencia en los individuos (cf. FRH 501).

Lo que se acentúa es la marcha desde lo social hacia lo individual, y más rigurosamente, hacia lo personal. Vuelve aparecer aquí el interés desde donde estamos leyendo la propuesta ellacuriana. Lo social afecta a lo individual, y lo afecta en una dirección bien precisa: en la autorrealización personal. Los individuos optan por una u otra forma de estar en la realidad, con la que actúan y esa actuación está en función de su realización personal, pero se trata de una realización social y socializante, por eso Ellacuría piensa que la tradición recibida y que configura la propia vida, puede ser personalizada, pero se trata de una recepción personal de lo social. La acción tiene un carácter social. Un carácter social por provenir del phylum, por estar afectado por la especie. Sin embargo, los hombres no viven de un modo aislado, sino que se realizan como personas conviviendo con los demás, en este sentido el phylum, la especie afecta también al grupo, aquí se marcha de lo social a lo social, por eso dice Ellacuría que "nos encontramos con una tradición reduplicativamente social: social por ser lo transmitido socialmente y social porque es recibido socialmente". Desde aquí se ve con más facilidad que se sostenga que en el proceso histórico lo que interviene es lo social (FRH 503).

En las personas hay una radical dimensión de individualidad, esfera que pueden hacer decir a un pensador como L. V. Mises, por ejemplo, que nadie está legitimado para decirnos en qué consiste la propia felicidad ${ }^{17} 0$, en terminología zubiriana, nadie está legitimado para decirnos en qué consiste nuestra propia realización personal. Pero se trata de una dimensión que se ve toda ella envuelta en el carácter social ${ }^{18}$ de esa individualidad.

$16 \mathrm{Al}$ respecto vale la pena recordar el tratamiento que hace de este asunto cuando aborda el problema del bien común y los derechos humanos, Ellacuría piensa que para santo Tomás "la bondad de una parte se considera en relación con lo que es su todo, y como el hombre es parte de la ciudad, es imposible que ningún hombre sea bueno sino por su relación al bien común". Sigue diciendo más abajo que "no hay voluntad recta en ningún hombre que busca un bien particular si no lo refiere al bien común como a su fin” Escritos Filosóficos III pp. 209-210.

17 Textualmente lo que dice Mises es que "nadie es capaz de dictaminar qué ha de proporcionar mayor bienestar al prójimo”, L.V. Mises, La acción humana, p. 40.

18 Preguntarse por cuál de las dos dimensiones tiene prioridad sobre la otra, es una pregunta 


\subsection{Impersonalidad de la historia}

Por importante que sea la dimensión individual en la biografía de cada cual, no son precisamente las acciones personales las que pasan a la historia, sino que lo que pasa a la historia es lo operado en esas acciones; toda acción realiza algo, ese algo es lo que pasa a la historia, es lo que Zubiri denomina el opus operatum (cf. FRH 504).

No es fácil distinguir entre acciones personales y acciones impersonales ${ }^{19}$. Quizá un ejemplo pueda ponernos en la pista de su diferencia para una correcta comprensión de este punto, importantísimo, para conceptuar con precisión la historia. Ellacuría escribió un libro, Filosofía de la realidad histórica ${ }^{20}$. Que muchas veces perdiera el humor, que pudiera pasar días, semanas e incluso meses sin poder producir nada, no son acciones que importen para una historia de la filosofía latinoamericana. Sin embargo, contar con un texto como el citado, ciertamente es de mucha importancia para aquella historia. Desde esta perspectiva, las primeras acciones, aquellas que dan cuentan de los cambios de humor del pensador, etc., pueden ser llamadas acciones personales, acciones de la persona, se trata de acciones que no pertenecen a la historia. Mientras que la segundas, escribir Filosofía de la realidad histórica, es una acción que entra de lleno a la historia, pero esas acciones son impersonales.

La razón última para que unas acciones pertenezcan a la historia y algunas otras no, estriba, en el hecho que sea el cuerpo social el que es el sujeto de la tradición social. Esto significa que los individuos operantes lo hacen como integrantes del cuerpo social, como vinculados en los otros en tanto que otros. Esto hace que lo histórico se evada de las personas en tanto que personas.

Por lo tanto, concluye Ellacuría, "los individuos y la sociedad confluyen en el campo de lo histórico; esto es, en la historia hay lugar tanto para la acción individual como para el cuerpo social". Se trata, insistamos en este punto, de acción individual en la que se considera su aspecto impersonal y de una acción del individuo como miembro de un grupo social, se trate de acción individual

ociosa. Lo social es congénere a lo individual. Lo individual tiene esencialmente un carácter social, y lo social tiene esencialmente un carácter individual. El empecinamiento por querer defender, unilateralmente, alguna de estas dimensiones indica que en rigor lo que importa es defender machaconamente una determinada ideología.

19 Las acciones personales tienen que ver con aquellas acciones de la persona; acciones impersonales tienen que ver con las acciones del ser humano. La persona no es histórica, es si se quiere biológica. El ser humano sí es histórico en tanto construye una personalidad. La personalidad se inscribe en el ámbito impersonal.

20 Es un libro publicado póstumamente por Antonio González, pero se trata de un libro de Ellacuría, A. González dice que "disponemos del grueso de su proyectada obra y, lo que es más importante, esto que nos ha quedado goza de unidad lógica y de relevancia filosófica”, FRH p. 10. 
o de acción del cuerpo social, el énfasis está en la dimensión impersonal de la acción. También hay que decir que seguimos moviéndonos en el horizonte de la praxis (cf. FRH 506).

\subsection{Posibilidades históricas}

Lo formalmente histórico es la entrega de formas de estar en la realidad. Esto se entiende en seguida si lo que se busca es distinguir entre la naturaleza y la historia. Lo biológico son las notas psíquicas y orgánicas y lo histórico son las formas de estar en la realidad. Lo histórico es que se le entregue al recién nacido una forma abandonada de estar en la realidad. ¿Qué tiene de histórico que un recién nacido sea abandonado a la entrada de un convento? La inquietud deja en evidencia que se trata no de esclarecer la dimensión material de la historia, sino que se trata de esclarecer su dimensión formal, o cómo se pregunta I. Ellacuría ¿qué es lo que ocurre formalmente en la transmisión de las formas de estar en la realidad? Hay que fijarse bien que la pregunta apunta justamente a lo que ocurre en la transmisión de formas de estar en la realidad. No se pregunta por las consecuencias que van a generar esas formas, sino lo que ocurre en ellas mismas (cf. FRH 519).

Por eso Ellacuría sigue afinando la pregunta: ¿qué es lo formalmente histórico? En el apartado anterior se adelantó la respuesta a esta interrogante cuando se dijo que al hablar de formas de realidad a lo que se estaba haciendo referencia era a las posibilidades. Lo que importa señalar es que cuando se dice que se trata de lo formal de la entrega de formas de realidad, lo que se quiere evitar es el error de entender las posibilidades desde su contenido. Formalmente las formas de realidad son posibilidades. Entonces ¿qué se entiende por posibilidades? Al finalizar la guerra civil salvadoreña a inicios de los noventa, se le ofreció a esa generación la forma de estar pacíficamente en la realidad, la forma de estar corruptamente en la realidad ${ }^{21}$, la forma de estar ociosamente ${ }^{22}$ en la realidad, etc., etc. Se les entregaron formas de estar en la realidad. Esto no significa que aquellos seres humanos estuvieran inexorablemente forzados a tener que realizar una determinada forma de realidad, entonces ¿qué fue lo que se les entregó? se les entregó un poder optar (cf. FRH 521).

La entrega de un poder optar es lo que permite hablar de posibilidades y no de posibilidad. Si en la realidad se entregara una sola posibilidad por muy forma de realidad que fuera, no podríamos hablar de la entrega de un poder, a los hombres

21 En tanto las estructuras de corrupción no fueron desmanteladas con los acuerdos de paz, esas estructuras siguen vigentes en la actual situación que nos toca vivir.

22 Entiendo por ocio el que los jóvenes estén sin realizar ningún tipo de actividad productiva, y se dediquen a pasar el tiempo. 
no les quedaría más remedio que asumir aquella posibilidad ${ }^{23}$. Pero como lo que en rigor ocurre es que se entrega un sistema de posibilidades, entonces la entrega es de un poder, un poder optar entre dos o más posibilidades. Pero supongamos el caso de que haya un sistema de posibilidades ${ }^{24}$ ante una realidad que no cuenta con el poder optar, de nada servirían dichas posibilidades, esto significa que las posibilidades, como dice Ellacuría, necesitan del poder de opción, para pasar a la acción y con la acción para pasar a su plena realización. Las posibilidades son posibilidades para actuar, pero se trata de una acción que supone un poder actuar.

En todo caso es la opción la que permite que las posibilidades pasen a la realidad efectiva, por eso Ellacuría continua diciendo que las "posibilidades no se constituyen en un puro acto de pensamiento, sino que son posibilidades de la realidad $^{25}$, son posibilidades de las cosas, aunque no se descubran, sino respecto de una inteligencia sentiente; son además posibilidades de la vida real, aquello con que la vida humana debe hacerse y aquello, consecuentemente, con que el ser humano ha de realizarse" (FRH 523).

Las posibilidades están en la realidad, porque si no estuvieran en ella difícilmente podría el hombre enfrentarse con ellas. Sin embargo, también hay que decir, que en la práctica esas posibilidades no son aprehendidas por todos, es común afirmar que muchos sólo ven dificultades y problemas ${ }^{26}$ donde otros, los pocos, ven posibilidades.

Como dice Ellacuría, hay un doble juego entre lo que las cosas pueden ofrecer desde ellas mismas al hombre y lo que el hombre puede hacer saltar de ellas como posibilidades. ¿Cómo se explica dicho fenómeno? Las posibilidades sólo se actualizan cuando una inteligencia se enfrenta con la realidad, cuando una inteligencia se hace cargo de la realidad. Lo que ocurre es que nos enfrentamos con esta realidad. Es decir, con una realidad concreta, con una realidad particular, en nuestro caso, con la realidad salvadoreña. Es precisamente en

230 rechazarla, siempre estamos en el ámbito de las posibilidades y no de la posibilidad.

24 Se hace como artilugio explicativo, porque el mismo hecho de que algo se aprehenda como posibilidades implica que esa realidad tiene el poder de optar por esas posibilidades. Sin embargo lo que aquí nos interesa exponer es la radical unidad entre posibilidades y poder

25 Hay que señalar que este punto aparece más claro en el tratamiento que hace Ellacuría de las posibilidades que el realizado por el mismo Zubiri. Cuando el pensador español aborda el tema de las posibilidades lo hace como aquello que se actualiza en la inteligencia. Desde esta perspectiva, las posibilidades son consideradas en su actualización en la aprehensión. Porque si no fuera ese el caso difícilmente hubiera podido superar el realismo ingenuo de la antigüedad clásica X. Zubiri, IRA p. 304.

26 Entiendo por problema lo que usualmente se entiende cuando en la conversación cotidiana se dice que la vida está llena de problemas. No estoy haciendo referencia a ninguna interpretación etimológica de la palabra. 
esa realidad en la que se actualizan las posibilidades, y las posibilidades se actualizan en el enfrentamiento con las cosas. Con las cosas propias de esa realidad. Tampoco son cosas en general, sino unas cosas muy concretas, las cosas cotidianas, las cosas con las que estos hombres concretos hacen su vida. Por eso Ellacuría continua diciendo que "son las cosas las que en su trato con ellas se nos hacen presentes como posibilidades y ese trato con las cosas es un trato efectivo con ellas y no se funda en un mero ejercicio teórico de la razón.

El modo como Ellacuría entiende el trato efectivo con las cosas hace referencia a la ineludible tarea de dar cuenta, por ejemplo, de la vida económica, política, o cultural, de esta sociedad concreta. En otras palabras, se refiere al trato que hay que establecer con un salario que difícilmente llega hasta el fin de mes, con una situación en la que se asesina a quien no está de acuerdo con el régimen ${ }^{27}$, y con una situación ideológica que no sólo no describe la realidad, sino que la enmascara. Son las cosas con las que estos hombres concretos hacen su vida (cf. FRH 523).

\subsection{Apropiación de posibilidades}

No se trata de cosas ajenas a la vida de los seres humanos, tampoco se trata de cosas que puedan verse desde fuera de la situación concreta en la que están aquellos hombres, sino que se trata de los asuntos con los que hace su vida, por eso las posibilidades tienen un ineludible momento de apropiación. Se trata de una relación que vincula íntimamente al hombre y la posibilidad por la que opta, esa posibilidad se hace propia, entra a formar parte fundamental con su vida, no puede ser de otro modo dado que las posibilidades solo emergen de esas cosas reales con las que nos ha caído en suerte hacer la vida, por eso Ellacuría dice que si las posibilidades se realizan a través de la opción, lo que hago al realizar posibilidades es hacerlas mías, apropiármelas (cf. FRH 524).

Como el problema que estamos esclareciendo es el que tiene que ver con la historia, es legítimo preguntarse si la apropiación tal como ha sido expuesta es histórica. Es decir, por el modo en el que se ha presentado el tema de la apropiación pareciera que se trata de una asunto estrictamente personal, pero si este fuera el caso, por muy sugerente que fuera el tema de la apropiación no nos serviría para conceptuar con precisión la noción de historia, por eso Ellacuría se ve forzado a señalar que la impersonalidad de la historia hace referencia esencial a lo estrictamente personal, tal como lo estrictamente personal aparece en la apropiación; la apropiación, a su vez, lleva forzosamente

27 Más atinado es decir con una situación política en la que los políticos se han vuelto profesionales de la política. 
a la impersonalidad de lo histórico dada que la realidad concreta, tiene que objetivarse (cf. FRH 527).

Quizá sea un individuo humano el que se apropia de determinada posibilidad, o quizá sea un grupo humano el que realiza esa apropiación, pero una vez llevado a cabo el proceso de apropiación, y dado que es lo que les permite actuar tanto a los individuos como a los grupos, aquella apropiación rebasa los límites de cualquier vida personal o de cualquier grupo. Que la ciencia moderna, con Galileo a la cabeza, se haya apropiado de la manera matemática de conocer la naturaleza, ha sido algo que rebasó los límites de la física de Galileo y encarriló toda la historia de la ciencia hasta nuestros días, a eso es a lo que se refiere Ellacuría cuando establece que la apropiación tiende a objetivarse ${ }^{28}$.

Interesa dejar constatado que la referencia a la apropiación es esencial para entender el todo de la realidad histórica. Sin apropiación, dice Ellacuría, no habría historia. En la apropiación puede verse uno de los vectores de la historia: lo histórico exige, por su propia índole un momento de apropiación. Más rigurosamente la apropiación es histórica, no por lo que tiene de opción personal, sino por lo que tiene de actualización de posibilidades, mientras que la opción es personal, no por lo que de histórico tengan las posibilidades, sino por lo que tienen de libres en su carácter mismo de posibilidades necesitantes (Cf. FRH 527).

\subsection{Dinamismo de la posibilitación}

Hemos hecho referencia en lo que va de este artículo a sucesos reales en la vida del pueblo salvadoreño. Hemos dicho que se trata de un conjunto de posibilidades que se les ha entregado a las generaciones que les ha tocado en suerte vivir en la era de postguerra, también hemos dicho que se trata estrictamente de posibilidades en el sentido que contamos con un conjunto de ellas, conjunto en el cual la una es respecto de la otra, y en tal sentido contamos con un sistema de posibilidades.

Desde esta perspectiva, podemos propender a pensar que entendemos adecuadamente lo que ocurrió, por ejemplo, con los Acuerdos de Paz dando cuenta del sistema de posibilidades con el que contamos. Sin embargo, esto con ser importante no es suficiente para entender aquel suceso, por eso Ellacuría dice que "entender un suceso no es sólo conocer sus causas, sino conocer el proceso por el cual una posibilidad realizada es principio de la posibilidad de otras" (cf. FRH 529).

28 Lo mismo podemos decir de Aristóteles: el que se haya apropiado de un concepto de filosofía como estricto y riguroso saber de las cosas, fue algo que no sólo le permitió entender su propia idea de Filosofía, sino que de algún modo orientó toda la historia ulterior de la filosofía (cf. CLF 16). 
Que se haya podido celebrar Acuerdos de paz sólo pudo ser posible a partir de las posibilidades ofrecidas por el pasado, pero una vez apropiada la posibilidad de la paz, va a convertirse en desencadenante de un proceso que en su día aportará nuevas posibilidades, por lo tanto sólo podemos entender un suceso si podemos dar cuenta de las posibilidades que lo posibilitaron, de las posibilidades posibilitantes, y de estas posibilidades como principio de nuevas posibilidades, por eso continua diciendo Ellacuría que "el dinamismo propio de la historia es un dinamismo de posibilitación (cf. FRH 530).

\subsection{El poder como posibilitante}

¿Qué es la historia? ¿Es la historia un catálogo de sucesos? ¿Es la historia salvadoreña el recuento de los sucesos que le han acaecido: matanza del 1932, dictadura de Martínez, guerra del futbol, guerra civil, Acuerdos de paz, etc.? ¿Qué hay en todas esas vicisitudes que nos permita considerarlos históricos?

La matanza de 1932 no se agota en sí misma, sino que para entenderla, como hemos dicho, hay entender aquello que la generó y entender el dinamismo por ella generado. En este sentido hay una estricta vinculación entre la situación anterior a 1932, $1932^{29}$ y después de 1932. Esta vinculación tiene un nombre riguroso, es proceso. Por lo tanto, una característica esencial de un suceso para ser considerado histórico, es su carácter procesual. Si nos replegamos en lo que la historia tiene de proceso, es decir, si quedamos retenidos en el aspecto procesual de la historia, descubrimos que no podemos acceder a $C$, dándole un rodeo a $\mathrm{B}$; llegar a $\mathrm{C}$ implica pasar, necesariamente, por $\mathrm{B}$. El acento está en ese no poder, por eso Ellacuría dice que la historia es un proceso de lo que el hombre puede o no puede hacer (cf. FRH 536).

Lo importante en la historia no es su contenido material, o, en otras palabras la serie de vicisitudes por las que ha tenido que pasar el hombre o la sociedad, sino que está en el poder con el que cuenta, hay que disponer de un poder. Todo el problema está en esclarecer ¿qué es este poder? La pregunta por el poder es una pregunta que se hace el hombre prácticamente desde que es hombre. Una de las primeras dificultades que tuvo que encarar fue precisamente los incomprensibles poderes de la naturaleza, cómo es posible que las cosas cambien, la genialidad del antiguo griego fue caer en la cuenta que la causa de las modificaciones que sufren las cosas, hay que buscarla en las cosas mismas, son las cosas el principio de sus cambios, a ese principio fue a lo que los primeros

29 Roque Dalton lo dice de modo brillante: "Todos nacimos medio muertos en 1932, sobrevivimos pero medio vivos, cada uno con una cuenta de treinta mil muertos enteros". Todos, son todos, es decir, los de 1932 y todos los demás salvadoreños que nacieron después de esa fecha. R. Dalton, Las historias prohibidas del pulgarcito, p. 124. 
pensadores griegos llamaron physis, naturaleza. En la semilla está el poder de convertirse en árbol, la semilla es un árbol en potencia, el poder consiste en ser potencia, lo posible es lo potencial. En el caso de los seres humanos también hay una especie de poder constituido por la radical unidad de dos potencias: la sensibilidad y la intelección; una intelección que es sensible y una sensibilidad que es intelectiva, es la inteligencia sentiente como facultad, dice entonces Ellacuría que cuando el poder es facultad, lo posible es lo factible (cf. FRH 538).

Sin embargo, ni el poder como potencia ni el poder como facultad son estrictamente históricos. Nos movemos en este caso en el ámbito de la naturaleza, pero es importante constatarlo porque sin aquellos poderes difícilmente sería posible conceptuar el poder histórico. Los salvadoreños no viven hoy en paz $^{30}$ solamente porque poseen unas potencias y unas facultades. Esas potencias y esas facultades las han poseído todos los hombres en todos los tiempos y lugares, y no por ello han vivido en paz. Por lo tanto, para encontrar ese poder con el que podemos vivir en paz, hay que volver la vista a las posibilidades, pero en lo que tienen de posibilitante, no todas las posibilidades posibilitan las paz, incluso algunas podrían posibilitar la discordia, sólo algunas de esas posibilidades son las posibilitantes, tienen el poder de posibilitar la paz, desde esta perspectiva, el poder es lo posibilitante, es lo posible como posibilidad (cf. FRH 538).

¿Qué es esta posibilidad? el psiquismo y el organismo, la sensibilidad y la intelección, son notas esenciales a la realidad humana, pero ¿son las posibilidades notas nuevas de aquella realidad, además de psiquismo y organismo tiene un nuevo sistema de notas constituido por sus posibilidades? Recurramos a un extenso texto en el que se contesta a esta inquietud. Ellacuría dice que lo posibilitado significa que un sujeto no sólo está ya facultado para hacer algo, y que sus potencias ya están facultadas para hacerlo, sino que cuenta con un factor, que siendo en principio extraño, es indispensable para, mediante su apropiación, poder hacer lo que antes no podía: no sólo está facultado, sino que está posibilitado, está realmente posibilitado sin que esa posibilitación implique la adquisición de una nueva nota ni constitutiva ni adventicia ( $c f$. FRH 539).

Hay que insistir que aquí importa dejar establecido que las posibilidades no son notas nuevas en la realidad humana. En el afán por explicar cómo es el modo en el que están las posibilidades en la realidad humana o si se quiere 
en la realidad, Ellacuría recurre a una noción que es clave en la filosofía zubiriana, nos referimos a la noción de actualidad ${ }^{31}$. Las posibilidades, comienza recordando el filósofo, son de la realidad humana y en la realidad humana, son actualidades que antes no estaban y ahora están (cf. FRH 543).

¿En qué consiste el poder de posibilitación? Si las posibilidades son de la realidad, significa que es la realidad la que funda las posibilidades, y que las posibilidades están fundadas en aquella, se da aquí una relación de fundante, la realidad, y de fundado la posibilidad, en la unidad entre lo fundante y lo fundado se encuentra el poder de posibilitación. Las posibilidades no son nuevas notas de las cosas, el poder posibilitante estriba en que las posibilidades se fundan en la realidad, el poder posibilitante reside precisamente en el hecho de que las posibilidades no se apoyen en el aire sino en que tengan su rigurosa apoyatura en la realidad (cf. FRH 543).

El poder posibilitante reside, recuerda Ellacuría, en que la vida no puede fantasear posibilidades sin cuento, si no que se trata de posibilidades de vida, posibilidades de historia (cf. FRH 545).

\subsection{Las dotes y las capacidades.}

El poder posibilitante lo posee las posibilidades, ¿Cómo afecta ese poder posibilitante a las potencias y facultades de la realidad humana? Dice Ellacuría que las afecta dotándolas. Al modo como el poder posibilitante afecta a las potencias y a las facultades, lo llama dotes. ¿Qué es la dote? Es la que hace posible lo que antes no era posible. Entendiendo lo posible al menos en dos direcciones, como objeto posible y como todo lo que es posible hacer con ese objeto en la vida de cada cual, en la vida del grupo, etc. Lo posible es aquello que confiere una forma de estar en la realidad. Esto significa que la realidad humana está dotada pero con aquellas dotes está abierta a diversas maneras de estar en la realidad, la dote no determina unívocamente una única respuesta sino que del modo como está dotado opta por un modo de estar en la realidad, en este sentido dice Ellacuría, la posibilidad queda incorporada (cf. FRH 546).

El problema que aquí hay que esclarecer es la índole de esa incorporación. Los hombres se apropian posibilidades, unas $u$ otras pero inexorablemente lo han de hacer para poder realizarse como realidades humanas. Al apropiarse

\footnotetext{
31 La noción de actualidad es una noción que comenzó a tener un tratamiento sistemático en Sobre la esencia y se hizo inundatorio tanto en "La dimensión histórica del ser humano" como en las "Reflexiones sobre la eucaristía", nos estamos refiriendo a textos que corresponden a la madurez filosófica de Zubiri. Por esta razón, es por la que hemos defendido que la noción de posibilidades ocupa un lugar central en la filosofía zubiriana.
} 
posibilidades las hacen suyas, se las apropian, las incorporan a su realidad. Pero se incorporan como principio de posibilitación. A la incorporación de posibilidades como principio de posibilitación es a lo que se denomina capacitación. Las posibilidades afectan a las potencias y facultades dotándolas, pero un modo concreto de dotarla es capacitándola (cf. FRH 548).

\subsection{El proceso de capacitación}

Aunque el modo de tratar los temas anteriores da la impresión que se trata del mero juego de apropiación de las posibilidades por parte de los individuos hay que decir que se trata también de un proceso propio de los grupos (cf. FRH 550).

Es verdad que los Acuerdos de paz se firmaron en 1992, sin embargo, el diálogo era un tema del que se hablaba desde el inicio de la década de los ochenta ${ }^{32}$, es probable que se hubiera podido firmar dichos acuerdos en ese entonces, pero nada garantiza que se hubieran tenido los mismos resultados que se obtuvieron al ser firmados una década después ${ }^{33}$.

Esto es verosímil decirlo sobre todo si se toma en cuenta la historia de la filosofía. Esta disciplina surge en dos puntos distintos del planeta casi al mismo tiempo, nos referimos a la India y a Grecia, en ambos lugares los pensadores quedan retenidos, asombrados contemplando el espectáculo de la totalidad del universo, sin embargo, la filosofía como ciencia sólo pudo surgir en Grecia, mientras que en la India se convirtió en un saber operativo mediante el cual o se evadía o se identificaba el pensador con el fenómeno. Es decir, fue la reflexión griega la que va a decantar toda la reflexión filosófica occidental, no ocurrió lo mismo con el pensamiento indio ${ }^{34}$. Se debió al modo preciso como estaba capacitada la cultura griega ${ }^{35}$.

32 "En El Salvador, el diálogo no es una bella palabra genérica y humanista. Es una propuesta concreta, que implica unos interlocutores precisos con temas determinados y un objeto claro. Es el diálogo entre las partes comprometidas en el conflicto, que quieren discutir aquellas condiciones mínimas que fueran suficientes para terminar con la violencia y empezar la difícil tarea de la reconstrucción moral, económica y política de El Salvador", I. Ellacuría, "El diálogo en El Salvador como principio de solución política”, p. 997.

$33 \mathrm{H}$. Samour lo explica en estos términos: "dar sentido a un hecho histórico sería mostrar cómo ese suceso tuvo que aparecer en ese momento o, al menos, que sólo pudo aparecer en ese momento", Op. Cit. p. 102.

34 Cf. X Zubiri, NHD. p. 206-207.

$35 \mathrm{M}$. Weber, por su parte se pregunta "¿qué serie de circunstancias han determinado que precisamente sólo en Occidente hayan nacido ciertos fenómenos culturales, que [...] parecen marcar una dirección evolutiva de universal alcance y validez?" y responde que se "trata de un racionalismo específico y peculiar de la civilización occidental" M. Weber., La ética protestante, pp. 5 y 17. 
Entonces, es verosímil que en los ochenta se hubieran firmado acuerdos de paz, pero quizá la paz no hubiera sido tan duradera. ¿Por qué pueden ocurrir las cosas así?, la respuesta es que las capacidades sólo surgen apoyadas en otras capacidades, se trata de capacidades muy determinadas, por eso una misma acción es históricamente distinta según el momento en que tenga lugar, según el momento procesual que se efectué. Por eso dice Ellacuría que la historia es un proceso físico y metafísico de capacitación (cf. FRH 550). ¿En qué medida en un proceso metafísico? En la medida en la que aparecen no sólo haceres nuevos, sino poderes nuevos de hacer respecto de formas de estar en la realidad. Una realidad que en tanto realidad aparece en un nivel nuevo ( $c f$. FRH 552).

\subsection{Proceso creacional}

La historia como toda otra realidad es un proceso apertural, es una creación novedosa de posibilidades, incluso creación de sistemas de posibilidades. En este punto es donde se manifiesta toda la importancia de la noción de posibilidades, no sólo para una filosofía de la historia, sino para la relevancia de la filosofía como disciplina que busca conocer la realidad de las cosas. La historia es algo que se va construyendo, es un proceso abierto e inacabado, llena toda ella de posibilidades por alumbrar y por construir, en este sentido la historia es una fuente inagotable de esperanza aunque para ser completos, recuerda Ellacuría que este carácter procesual de la historia es el que hace de ella un riesgo permanente. Es un riesgo cada vez más grave, porque las posibilidades son cada vez más englobantes, mientras que las oportunidades más escasas y difíciles ${ }^{36 " . ~}$ De todos modos la noción de posibilidades permite apostar por una noción de historia en la que pueda construirse un mundo capaz de darle abrigo humano a todos los hombres y mujeres. Por ello, hay que preguntarse, para ir concluyendo este artículo, por este proceso creacional. Respecto a ello hay que acentuar dos cosas: que se trata de un auténtico proceso, por lo tanto hay que recordar los momentos de ese proceso y que se trata además de un proceso histórico. En primer lugar se trata de un proceso, es decir, los productos más formalmente históricos aparecen en una rigurosa fundamentación. La ciencia y la técnica son hoy, por ejemplo, las mayores posibilidades con las que contamos, sin embargo el carácter creativo de la historia no radica en el plano de esos productos como posibilidades en tanto que están fundados en las capacidades (cf. FRH 559).

En segundo lugar se trata de un proceso histórico. Las capacidades no se encuentran de modo virtual en la realidad, ni tampoco al modo de germen, la

36 Más adelante sigue preguntándose Ellacuría si los poderes desarrollados en la historia sean los verdaderos poderes que necesita la humanidad para humanizarse, porque los poderes piensa este filósofo, pueden ser utilizados tanto para construir como para destruir (cf. FRH p. 563). 
historia no es un desenvolvimiento de lo que se encuentra virtualmente en la realidad sino que lo formalmente histórico tiene que ser creado por una acción en la que no sólo se crea algo nuevo, sino que constituye un nuevo principio de acción, las capacidades. Sin acción no solo no habría historia, sino que tampoco podría haber vida humana (cf. FRH 561).

\section{Conclusión}

Aunque la exposición que hemos hecho de la noción de posibilidades en Filosofia de la realidad histórica trata un tema central en la filosofía zubiriana, queremos señalar que el esfuerzo de Ellacuría no se limita a recoger unos determinados contenidos, unos determinados problemas zubirianos, sino que es un esfuerzo que parte de la misma raíz de la que partió Zubiri: una reflexión sobre las cosas tal y como se actualiza en la aprehensión. Por esta razón es por la que Ellacuría es zubiriano y no porque recoja, más o menos genialmente, unos problemas tratados por Zubiri.

El hecho que se le actualiza en la aprehensión es la categoría de praxis histórica, es precisamente por ello que encuentra, no sólo central sino relevante el tratamiento de la noción de posibilidades. Esta noción se precisa cuando Ellacuría aborda las fuerzas históricas, se trata de las fuerzas que mueven la historia en una dirección u otra ( $c f$. FRH 568-574). De fuerzas que se constituyen en posibilidades. Al respecto comenta que "las que hemos llamado fuerzas sociales, económicas, culturales y políticas son posibilidades históricas, porque son resultado de un proceso histórico y porque de suyo se actualizan como tales" (cf FRH 576).

En el tratamiento que hace Ellacuría de esta noción prima su comprensión como posibilidades reales, posibilidades entregadas por la sociedad a los individuos y a los grupos humanos. Grupos que tienen que optar por esas posibilidades, acto mediante el cual las hacen suyas, se apropian, dotándolos de una capacidad con la que pueden construir nuevos sistemas de posibilidades. Esas posibilidades son la condición, el supuesto de la praxis histórica.

\section{Bibliografía}

Dalton, Roque., Las historias prohibidas del pulgarcito, UCA Editores, San Salvador 1988.

Ellacuría, Ignacio, Escritos Filosóficos III, UCA Editores, San Salvador 2001.

Ellacuría, Ignacio., Filosofía de la realidad histórica, UCA Editores, San Salvador 1999. 
Mises, Von Ludwig., La acción humana, Centro de Estudios Sobre la Libertad, Buenos Aires 1980.

Samour, Héctor., Voluntad de liberación, la filosofía de Ignacio Ellacuría, Editorial Comares, Granada 2003.

Weber, Max., La ética protestante, Ediciones Península, Barcelona 1973.

Zubiri, Xavier., Naturaleza, Historia Dios, Alianza Editorial, Madrid 2007.

Zubiri, Xavier, Inteligencia y razón, Alianza Editorial, Madrid 2001.

Zubiri, Xavier., Sobre el Hombre, Alianza Editorial, Madrid 2007.

Zubiri, Xavier., Cinco lecciones de filosofía, Alianza Editorial, Madrid 2009. 